\author{
Pau Freixa Terradas (iD https://orcid.org/0000-0002-1906-8983 \\ Universitat de Barcelona \\ paufreixa@ub.edu
}

\title{
Wyklęcie Papuszy według Angeliki Kuźniak, czyli biograficzny reportaż jako esej
}

\author{
Papusza's Condemnation According to Angelika Kuźniak or the Biographic \\ Reportage as an Essay
}

\begin{abstract}
The following article deals with the literary biographical reportage Papusza and the author's impression of the Gypsy poetess. Kuźniak explores Papusza's life beyond the myth rooted in popular culture. And in her search for the real Papusza she finds an absolutely tragic figure. Naturally, the author applies a highly critical feminist gaze that detects the "sins" for which the poetess will have to "pay", and in general these are related to the fact that she is a woman. But there is no discourse here: the author makes the facts speak for themselves. The plot is constructed in such a way that the moral commentary is redundant. Kuźniak's work is a dry, minimalist book, built upon bare factsand scraps of life, with no apparent literary work: its stylisation is expressed through linguistic coarseness, imitating Papusza's austere way of life (a life where the poetry is sought after), her primitive writing and even her naïve poetry. As we shall see, three great condemnations loom over Papusza's life: femininity, gypsyness and otherness. But Kuźniak goes beyond the specific biographical account, which in turn serves as a micro-historical vector through which we gain access to a vision of the history of Polish Gypsies in the twentieth century. Thanks to that Papusza thus becomes a critical essay dealing with the issues of discrimination, gender and otherness.
\end{abstract}

Keywords: Angelika Kuźniak, Bronisława Wajs Papusza, Polish school of reportage, biographic reportage, non-fiction literature

Streszczenie: Poniższy artykuł poświęcony jest literackiemu reportażowi biograficznemu Papusza i obrazowi romskiej poetki, który tworzy jego autorka. Angelika Kuźniak bada losy Papuszy poza mitem utrwalonym w kulturze popularnej, a poszukując Papuszy z krwi i kości, trafia na postać absolutnie tragiczną. Co oczywiste, autorka prezentuje niezwykle krytyczne spojrzenie feministyczne, które wychwytuje grzechy, za które poetka będzie musiała zapłacić, a na ogół są one związane z faktem bycia kobietą. Ale tu nie ma publicystyki, autorka sprawia, że fakty mówią za siebie. Fabuła jest tak skonstruowana, że komentarz moralny jest zbędny. Jest to książka sucha, minimalistyczna, zbudowana na czystych dokumentach i skrawkach życia, pozornie bez obróbki literackiej: jej stylizacja wyraża się w językowej zgrzebności, 
jakby naśladującej twarde życie Papuszy (życie, w którym szuka się poezji), jej prymitywne pismo, a nawet jej ubogą i naiwną poezję. Jak zobaczymy, w losie Papuszy spotykają się trzy wielkie anatemy: kobiecość, cygańskość i inność. Ale Kuźniak wykracza poza konkretną relację biograficzną, która z kolei służy jako wektor mikrohistoryczny, dzięki któremu uzyskujemy dostęp do wizji historii polskich Romów w XX wieku. W ten sposób Papusza staje się esejem krytycznym dotyczącym dyskryminacji, płci i inności.

Słowa kluczowe: Angelika Kuźniak, Bronisława Wajs Papusza, polska szkoła reportażu, reportaż biograficzny, literatura faktu

\section{1}

Kto pamięta dziś Papuszę, cygańską poetkę? Oczywiście, jej nazwisko jest nadal znane i można nawet powiedzieć, że zajmuje szczególne miejsce w polskiej zbiorowej wyobraźni kulturowej jako postać publiczna, która wypełnia zredukowaną przestrzeń zarezerwowaną dla romskiego pisarza. Poetka funkcjonuje jako rodzaj ikony tej możliwości, że ktoś należący do mniejszości narodowej kojarzonej z marginalnością i analfabetyzmem może pisać wiersze. Ale o ile w jej czasach ważne postaci polskiej literatury, takie jak Julian Tuwim i Wisława Szymborska, dostrzegały w twórczości Papuszy szczególny talent, o tyle dziś Papusza jako pisarka pozostaje nieco zapomniana, a jeśli jej twórczość poetycka ma pewną nośność, to tylko zamkniętą w etykiecie „Cyganki”. A jednak jako ikona kultury romskiej we własnej społeczności, ale przede wszystkim na zewnątrz, w kulturze polskiej, pozostaje postacią rozpoznawalną i emblematyczną. To właśnie ta ikoniczność wraz z egzotyką figury i epicką siłą jej tragicznego losu zdają się przyczyniać do jej niepewnej, ale stałej obecności w zbiorowej wyobraźni Polaków. Za sprawą tych cech jej publicznego wizerunku stawała się bohaterką twórczości różnych współczesnych polskich artystów. Sama postać i jej historia były więc wielokrotnie odzyskiwane przez innych pisarzy czy reżyserów, którzy poświęcili jej kilka książek, reportaży telewizyjnych czy filmów (można tu wspomnieć o wielokrotnie nagradzanej Papuszy Joanny Kos-Krauze i Krzysztofa Krauzego z roku 2013). W niniejszym artykule chcę się skupić na utworze Papusza Angeliki Kuźniak ze względu na szczególną wizję postaci poetki i jej osobistej tragedii, ale przede wszystkim ze względu na sposób, w jaki konstruuje ona eseistyczny kontekst, poruszający wiele problemów, dla których przypadek Papuszy stanowi pouczający przykład. W tym sensie tekst Kuźniak wykracza daleko poza biografię Bronisławy Wajs, stając się gatunkowo czymś innym. Tylko właściwie czym?

Przede wszystkim należy zaznaczyć, że nie jest to typowa biografia, a raczej reportaż biograficzny. Kuźniak jest zresztą jedną z najwybitniejszych przedstawicielek tego podgatunku literackiego, tak bardzo popularnego w literaturze polskiej XXI wieku. W eseju Reportaż biograficzny czy biografia reportażowa? Refleksje genologiczne i analiza przypadku Edyta Żyrek-Horodyska podaje właśnie 
twórczość Kuźniak jako przykład krzyżowania się reportażu i biografii w wielu hybrydycznych formach:

Na gruncie badań medioznawczych i literaturoznawczych „biografia reportażowa”, „reportaż biograficzny” czy „opowieść biograficzna” funkcjonują niejako paralelnie jako określenia, które nierzadko przez krytykę, ale i samych autorów traktowane są synonimicznie. Przykładowo książka Marlene Angeliki Kuźniak zostaje przez Izabellę Adamczewską określona jako „forma przejściowa pomiędzy reportażem biograficznym a reporterską opowieścią biograficzną”, z kolei Magdalena Horodecka tom ten nazywa wprost „reportażem biograficznym ${ }^{1}$.

Również w Papuszy Kuźniak bierze za podstawę reportaż, by modelować portret poetki. Można dostrzec wiele cech tej książki, które są bliskie warsztatowi reportera, a dalekie od rzemiosła biografa: pojawienie się narratora/autorki w akcji i jej szczególna, choćby dyskretna charakteryzacja; obfite wykorzystanie świadectw i dokumentów, które nie są poddane obróbce; ubogi, ale w pewien sposób poetycki styl; przede wszystkim jednak swoboda w wykorzystaniu opowieści o Papuszy do omówienia spraw istotnych dla dzisiejszego czytelnika, co prowadzi analizę biograficzną aż do bram eseju socjologicznego. Właśnie to ostatnie sprawia, że odczytanie przez Angelikę Kuźniak losów Bronisławy Wajs jest tak interesujące i uniwersalne. Pozostawiając nieco na boku zastosowane zabiegi estetyczne - analizowane między innymi przez Arletę Galant ${ }^{2}$, Izabellę Adamczewską ${ }^{3}$, Magdalenę Horodecką ${ }^{4}$ czy Edytę Żyrek-Horodyską ${ }^{5}$ - skupię się tutaj na subtelnie eseistycznym ładunku, jaki zawiera ta książka, a który znacznie wykracza poza jej biograficzną zawartość.

Angelika Kuźniak opowiada w Papuszy historię fascynującą i jednocześnie ogromnie smutną. Jest to swego rodzaju reportaż literacki, który przedstawia nam biografię cygańsko-polskiej poetki Bronisławy Wajs, bardziej znanej jako Papusza („lalka" w języku romskim). Na jego stronach poznajemy nieszczęśliwe życie Papuszy: dzieciństwo i młodość w taborze, nauka czytania i pisania opłacana kradzionymi

${ }^{1}$ E. Żyrek-Horodyska, Reportaż biograficzny czy biografia reportażowa? Refleksje genologiczne i analiza przypadku, „Autobiografia. Literatura. Kultura. Media ” 2018, nr 2 (11), s. 168.

${ }^{2}$ A. Galant, „Życie a życie to jest duża różnica”. O biografiach Bronistawy Wajs - Papuszy, „Autobiografia. Literatura. Kultura. Media” 2014, nr 1 (2), s. 175-194.

${ }^{3}$ I. Adamczewska, Biografia reporterska w ujęciu komunikacyjnym na przyktadzie ksiażek Angeliki Kuźniak, „Annales Universitatis Paedagogicae Cracoviensis, Studia Poetica” 2016, IV, s. 164-185.

${ }^{4}$ M. Horodecka, Reportaż jako medium pamięci Innego na przyktadzie „Papuszy” Angeliki Kuźniak, „Tekstualia” 2017, nr 1 (48), s. 179-194.

${ }^{5}$ E. Żyrek-Horodyska, dz. cyt., s. 165-185. 
kurami, przyjaźń z poetą Jerzym Ficowskim i początki poezji, stopniowe odrzucanie jej przez Romów traktujących ją jak zdrajczynię tajemnic swego ludu, zdobycie sławy (z czego sama nie zdaje sobie sprawy), która paradoksalnie sprawi, że własna grupa etniczna zastosuje wobec niej ostracyzm, a wreszcie długie lata samotności, nędzy i choroby psychicznej: Papusza umiera jako poetka o rozpoznawalnym dorobku, ale w całkowitej izolacji.

Ale, jak już zauważyłem, życie Papuszy jest dla Kuźniak kluczem, za pomocą którego otwiera i rozwija nowe, bardziej uniwersalne wątki. Pierwszy z nich to losy polskich Romów w XX wieku: tradycyjne koczownictwo, prześladowania i masakry dokonywane przez Niemców i Ukraińców w czasie drugiej wojny światowej, przymusowe osiedlanie w czasach komunizmu, panujący wśród znacznej części społeczeństwa polskiego rasizm itp. Kuźniak unika etnocentrycznego spojrzenia i nie idealizuje romskiego społeczeństwa, przeciwnie, stara się pokazać surowość tradycyjnego romskiego życia i niektórych jego zwyczajów, takich jak przyzwolenie na maltretowanie i wykorzystywanie kobiet. To prawda, że książka nieuchronnie emanuje aurą egzotyki, która czyni ją niezaprzeczalnie atrakcyjną dla czytelnika, ale Kuźniak robi to delikatnie, szukając tej cienkiej linii, tak charakterystycznej dla polskich reporterów, gdzie przecinają się żarliwość i dystans, trzeźwość i liryzm, obiektywizm reportera i deklarowana empatia wobec bohaterki ${ }^{6}$.

Ale to nie wszystko, bo przykład życia Papuszy, wpisany z kolei w losy polskich Romów w ubiegłym wieku, służy Kuźniak do zbudowania eseju krytycznego o znacznie szerszych ramach, o czym przekonamy się poniżej. Przyjrzyjmy się teraz sprężynom, na których osadzony jest ten dyskurs, ledwie naszkicowany w konkretnej treści książki.

Papuszę cechuje minimalizm formalny. W odróżnieniu od biografii powieściowej ta biografia zbudowana jest, jak kolaż dokumentów, z różnych głosów. Adamczewska definiuje jej gatunkową swoistość w następujący sposób:

O ile w Marlene (zwłaszcza w pierwszej części) opis researchu i wypowiedzi świadków miejscami dominują nad scenką, o tyle w Papuszy Kuźniak nie eksponuje ich tak wyraźnie, bardziej fabularyzuje. Z tego powodu zaliczyłabym Papuszę do reporterskich opowieści biograficznych. Podobnie jak Stryjeńska, której kompozycja

\footnotetext{
${ }^{6} \mathrm{Na}$ temat strategi „etnograficznej mimesis” warto przeczytać artykuł Magdaleny Horodeckiej Reportaż jako medium pamięci Innego na przyktadzie „Papuszy” Angeliki Kuźniak: „Lektura reportażu daje wrażenie wglądu do wnętrza kultury i sposobu jej doświadczania przez Romów. Wprawdzie pamiętnik jest obok pozostawionej przez Papuszę epistolografii i poezji tylko jednym z wielu źródeł wykorzystywanych w reportażu, ale intencja, którą ujawnia sposób posługiwania się przez reporterkę źródłami, wyraża się w dążeniu do uzyskania wrażenia bezpośredniego obcowania z Innym, jego percepcją świata. Kuźniak dąży do tego, byśmy zapomnieli, że o Cyganach pisze nie-Cyganka" (taż, dz. cyt., s. 184). Jak później zobaczymy, ta strategia etnograficznej mimesis, oprócz wywoływania w czytelniku iluzji „bezpośredniego wglądu w kulturę Innego i sposób jej doświadczania” (tamże, s. 194), służy również autorce do zbliżania się do bohaterki, do zbratania się z nią.
} 
opiera się na ciągu scen. Obrazek zdecydowanie dominuje, a utożsamiony z autorem narrator-reporter ukrywa się za rekonstrukcją zdarzeń, choć nie brak w książce reporterskich fragmentów ${ }^{7}$.

Obecność i praca narratora/autorki, która pojawia się również jako postać w roli badaczki/pisarki, zaznaczone są sporadycznie, ale w sposób znaczący. $\mathrm{Na}$ stronie 21 narrator, do tej pory ekstradiegetyczny, wkracza na scenę jako autorka, osoba z krwi i kości, z własną biografią, czyli jako Angelika Kuźniak, gwałtownie przechodząc z trzeciej osoby do pierwszej osoby rodzaju żeńskiego:

Miejsca. Twarze. Historia jak w błyskach. Zwodzi ją pamięć, szczególnie słaba do dat. To, co mówi, wywołuje nowe pytania. Nie na wszystkie znajdę odpowiedź. Są więc w mojej opowieści o Papuszy zdarzenia prawdopodobne, prawdziwe i wiele znaków zapytania. Nie zdążyłam z nią porozmawiać. Miałam trzynaście lat, gdy umarła $^{8}$.

Ale czy ten głos, który jest nam przedstawiany w tonie wyznania, jest głosem narratora, czy raczej samej autorki ? Tego rodzaju wystąpień nie ma w książce wiele (Kuźniak nie pisze o sobie) i pełnią one bardzo szczególną funkcję. Poprzez własną obecność w opowieści Kuźniak konstruuje narratorkę „empatyczną”" , jak to określa Adamczewska ${ }^{10}$, która przez swoje spojrzenie wartościuje właśnie postać protagonistki. Procedura ta ma istotne znaczenie w wypadku podmiotów, które zostały wyciszone, które a priori nie cieszą się uwagą czy nawet szacunkiem publiczności. To ucho, które słucha, ta obecność rozmówcy (Kuźniak nie znała Wajs osobiście i dlatego właśnie tak potrzebne jest podkreślenie sympatii, jaką czuje do bohaterki), pełnią funkcję pomostu między postacią wiktymizowaną a czytelnikiem. Jeżeli się nie mylę, ten reportażowy zabieg zainaugurowała Zofia Nałkowska w słynnym cyklu reportaży opartych na świadectwach ofiar Holocaustu - Medalionach. W swojej analizie opowiadania Przy torze kolejowym Aránzazu Calderón definiuje jako "głos społeczny" 11 taki podmiot narracyjny, który w relacji metonimicznej działa jako swoisty reprezentant świadomości zbiorowej. Nieco na wzór

${ }^{7}$ I. Adamczewska, dz. cyt., s. 185.

${ }^{8}$ A. Kuźniak, Papusza, Wołowiec 2013, s. 21.

9 A jeśli wierzyć samej Kuźniak, można by nawet mówić o „autorce empatycznej”: „Właśnie dlatego, że moje książki są tak skoncentrowane na emocjach, lubię je nazywać raczej portretami niż biografiami, nie interesuje mnie wyłożenie serii wydarzeń i już" (Angelika Kuźniak - io e Papusza, Intervista con Angelika Kuźniak, autrice della scuderia di Czarne specializzata in ritratti di donne speciali. Uno su tutti: Papusza (di Salvatore Greco), „PoloniCult, un blog italiano di cultura polacca”, 18.12.2017, https://polonicult.com/Kuźniak-papusza/, dostęp: 19.05.2021.

${ }^{10}$ I. Adamczewska, dz. cyt., s. 180.

${ }^{11}$ A. Calderón Puerta, Al otro lado del muro. Cuerpo y exclusión en "Junto a la vía del tren", de Zofia Natkowska [w:] Del instante a la eternidad: exégesis sobre "la espera" en la escritura de mujeres, red. J.L. Arráez Llobregat, A. Peral Crespo, Alacant 2012, s. 155. 
książek noblistki Swiatłany Aleksijewicz (najbardziej radykalny przypadek narratorki, która nie „mówi”, lecz jedynie „słucha” ${ }^{12}$ ) Papusza funkcjonuje jako rodzaj kolażu czy palimpsestu. Kuźniak nakłada na siebie różne tekstowe faktury o dokumentalnej naturze: niezliczone listy do Tuwima i Ficowskiego, intymny dziennik, który w ostatnich latach życia Papusza pisała z przerwami, nagrania do wywiadów, programów radiowych czy filmów dokumentalnych, zebrane przez autorkę świadectwa bliskich jej osób itd., w które wplata się głos narratorki tylko po to, by uporządkować, wyjaśnić, prawie bez wartościowania i interpretacji, ale - co ważne - dyskretnie zaznaczając swą obecność przy bohaterce. Czytelnik czuje się tu jak widz dramatu w realnym życiu, ledwie odroczonym przez przeniesienie na nośnik (papier, nagranie), który to prawdziwe życie utrwala. Co więcej, pisarstwo Kuźniak jest w tej książce tak szorstkie i bezpośrednie (ale też bliskie i czułe), jak poezja Papuszy, która zresztą pojawia się w narracji, niemal jako kolejny dokument. Mamy więc do czynienia z rodzajem literatury, która chce się upodobnić do życia, do czystego dokumentu, jakby autorka bała się zbytnio oddalić od opowiadanej rzeczywistości. W jednym z wywiadów Kuźniak tak tłumaczy ten proces kompozycyjny:

Zarówno Papusza, jak i Stryjeńska używały języka, który określał ich osobowość. Pisanie „z zewnątrz” nie pozwoliłoby nam być blisko bohaterek, tak myślę. A na tym mi zależało. Papusza, już i tak obca - bo Cyganka, bo poetka, bo pod koniec życia chora psychicznie - stałaby się jeszcze bardziej obca. U Stryjeńskiej trudno byłoby uchwycić furię, energię. W przypadku Papuszy miałam dodatkowo jej głos, kilkanaście godzin archiwalnych nagrań. Z nich montowałam monologi. Trochę jak w reportażu radiowym czy przy układaniu puzzli ${ }^{13}$.

Kuźniak chce bowiem widzieć w Papuszy kobietę, jaką była naprawdę, poza mitem, jaki wokół jej postaci zbudowała kultura oficjalna, a który w jakiś sposób przetrwał w zbiorowej wyobraźni kulturowej Polaków. A szukając tej Papuszy z krwi i kości, Kuźniak znajduje postać absolutnie tragiczną i właśnie taką Papuszę chce nam pokazać. Od razu zdajemy sobie sprawę, że pierwszą przyczyną jej tragedii jest jej płeć. W naturalny, nieunikniony można by powiedzieć sposób autorka prezentuje niezwykle krytyczne spojrzenie feministyczne, wyszukujące grzechy, za które Bronka Wajs będzie musiała zapłacić, a na ogół związane są one z faktem, że jest kobietą. Ale tu nie ma elementów publicystyki, autorka sprawia, że fakty mówią same za siebie. Jak to często bywa w dobrej literaturze

${ }^{12}$ Wciąż pamiętam, jak Aleksijewicz, zaproszona w 2016 roku na festiwal Kosmopolis w Barcelonie, uparcie odpowiadała na natrętne pytania rozmówcy - pisarza Francesca Serésa dotyczące procesu pisania. Tłumaczyła, że nie pracuje z piórem, tylko z dyktafonem, nic od siebie nie dodając.

${ }^{13} Z$ bohaterem muszę mieć chemię. Z Angelika Kuźniak rozmawia Justyna Czechowska, „Kultura Liberalna”, 26.01.2016, nr 368 (4), https://kulturaliberalna.pl/2016/01/26/z-bohaterem-musze-miec-chemie-angelika-Kuźniak/, dostęp: 17.05.2021. 
faktu, fabuła jest tak skonstruowana, że komentarz moralny okazuje się zbędny. Książka Kuźniak jest sucha, minimalistyczna, zbudowana ze strzępów życia, bez widocznej obróbki literackiej: jak już powiedziano, jej stylizacja wyraża się w zwięzłości, prostocie języka, jakby naśladowaniu surowego życia Papuszy (życia, w którym szuka się jednak poezji).

\section{3}

Przyjrzymy się zatem, temu, co pokazuje Kuźniak jako esencję życia Papuszy, gdyż właśnie problematyka wielostronnego wykluczenia świadczy o eseistycznym potencjale książki. Jednym z celów tego biograficznego reportażu wydaje się ujawnienie różnych wykluczeń i pokazanie, jak w skrajny sposób mogą one warunkować losy ludzi. Poprzez parabolę życiową Papuszy Kuźniak wykazuje, że najważniejsze wykluczenie dotyczy płci, a fakt bycia kobietą doprowadza w reakcji łańcuchowej do wielu wykluczeń, które nakładają się na siebie w rozmaitych aspektach i z różnymi skutkami. Książka bardzo wyraźnie ukazuje panujący w romskiej społeczności męski szowinizm: Papusza odkrywa go już jako dziecko, gdy bawiąc się w ojców i matki, chłopak, którego ma za partnera, bije ją i wysyła po pieniądze. W ten sposób Kuźniak wykorzystuje przykład Papuszy do konstruowania antropologicznego studium o nierównych stosunkach między płciami wśród polskich Romów, poszukując jednocześnie treści bardziej uniwersalnych. Romka jest systematycznie bita, niemal rytualnie, wykorzystywana w pracy, a jej ciało jest piętnowane (jak też wszystko, co ma kontakt z jej dolną częścią ciała: w centrum tabu znajduje się nieczysta pochwa, z której okresowo wydobywa się krew menstruacyjna; znany jest nawet przypadek Szero Rom, czyli króla cygańskiego, który został pozbawiony tytułu za pocałunek „tam, gdzie nie trzeba” ${ }^{14}$ ). Ale fakt, że jest kobietą, stanowi warunek sine qua non wszystkich innych uprzedzeń i wykluczeń, których Papusza będzie doświadczać przez całe życie, a które Kuźniak identyfikuje jako kręgosłup jej losu.

Z relacji Kuźniak o początkach przyszłej poetki jasno wynika, że Papusza jest/ musi być/ nie może nie być inna. Jej odmienność nazywa się nadwrażliwością, a może raczej kreatywnością. Papusza nie chce być inna, ale nie potrafi też swojej inności stłumić. To kwestia konieczności, jej buntowniczość nie jest dla niej wyborem. Stroni od konfrontacji ze społecznością i tradycją, ale nie może uciec od własnego powołania i bez możliwości ucieczki, z braku chęci, zdolności czy środków, skończy jako wyrzutek wśród wyrzutków. Pytanie, które odbija się echem w całej książce, brzmi: dlaczego Papusza nie staje się dezerterką - w znaczeniu nadanym temu terminowi przez Martine Leibovici, które tak dobrze się tu sprawdza ${ }^{15}-$

${ }^{14}$ A. Kuźniak, dz. cyt., s. 143.

15 „Dezerterzy (...), jednostki, których życie przeniosło je z jednej klasy społecznej do innej, z jednej kultury do innej, ze świata mniejszości do świata większości dzielącej uprzedzenia, często 
skoro jej popularność zdaje się dawać jej taką możliwość? Papusza czuje nieusuwalne przywiązanie do społeczności, która ją odrzuca, do dużo starszego, schorowanego, niekochanego, bijącego ją męża, który porwał ją, by uczynić z niej swoją żonę. Czy to przywiązanie do tego, czego się od niej oczekuje, działa jako cena za dostęp do tego, co jest jej zakazane: pisania wierszy?

Nauka czytania i pisania jest jedynie źródłem kpin; chęć decydowania o tym, kogo poślubić, spotyka się z dezaprobatą; nawiązywanie kontaktów z gadziem, z Innym, jest najpierw postrzegane jako podejrzane, a potem jako zdrada plemienia. Ale to, co jest nie do przyjęcia dla romskich mężczyzn i kobiet, to fakt, że jedna z nich jest niezależna, chce robić rzeczy, które nie są jej przeznaczone jako kobiecie, że jest wyjątkowa. Grzechem tu nie będzie pisanie wierszy (różne rodzaje mówionej poezji melicznej są powszechne wśród Cyganek), ale ich utrwalanie i rozprzestrzenianie poza romskim środowiskiem. Kiedy jej pieśni trafily do rąk poety Jerzego Ficowskiego, który je przetłumaczył i wydał, wszystkie oczy groźnie zwróciły się w stronę Papuszy. Nie godząc się na uległość, na jaką skazywały ją status kobiety i rola części w całości społeczności romskiej, Papusza chciała podejmować własne decyzje i realizować się twórczo, choć tak naprawdę nigdy nie miała zamiaru wyjść z anonimowości ani nie aspirowała do pozostawienia za sobą swojego romskiego przeznaczenia. Kiedy Ficowski zaczął pisać o Cyganach - co oni postrzegali jako odsłonięcie ich tajemnic - to właśnie na Papuszę spadł cały ciężar falorykty, czyli romskiej anatemy, a fakt, że była kobietą, w której zaszczepiono bezradność, miał, jak sugeruje Kuźniak, decydujące znaczenie: Bronisława Wajs była idealnym kozłem ofiarnym dla traumatycznego przejścia polskich Romów do nowoczesności ${ }^{16}$. Im bardziej Papusza stawała się sławna jako poetka wśród „ludzi kólturalnych" ${ }^{17}$, tym bardziej spotykała się z ostracyzmem ze strony własnego narodu. Ale na tym strasznym rozdrożu, gdzie musi wybrać między „ja” a „my”, Papuszy nie udaje się upodmiotowić w sensie empowerment i w końcu zostaje skazana na niemal całkowitą izolację. Załamanie zdrowia psychicznego poetki, którego genezę Kuźniak rzetelnie wyjaśnia, jest tylko jednym z wielu wydarzeń, które uniemożliwiają znalezienie wyjścia z jej rozpaczliwej sytuacji.

Z drugiej strony w całej książce przewija się także wątek wykluczenia ze względu na przynależność do mniejszości etnicznej i rasowej. Tworzy on oczywiste tło,

oszczercze lub nienawistne wobec tych mniejszości (...), zerwały one ze swoimi tradycjami i narracjami, wkraczając w świat, który się ich nie spodziewał i który nie ma żadnej narracji, mogącej nadać ramy ich wędrówce, poza narracją o wyjątkowej jednostce, której doskonałość jedynie uwypukla i wzmacnia utrwalone stereotypy, poprzez które postrzegana jest grupa, z jakiej się wywodzą" (M. Leibovici, Autobiographies de transfuges. Karl Philipp Moritz, Richard Wright, Assia Djebar, Paris 2013, s. 12 [ thum. - P.F.T.]).

${ }^{16}$ Do jakiego stopnia przyczynił się do tego fakt, że Papusza w swoich wierszy namawiała Romów do osiedlania? Do jakiego stopnia Papusza była wykorzystywana w tym celu przez władze PRL-u? Niestety, Kuźniak nie rozwija zanadto tego tematu.

${ }^{17}$ A. Kuźniak, dz. cyt., s. 138. 
które pozwala wyobrazić sobie koszty ewentualnej ucieczki do polskiego społeczeństwa. Zapewne nie spotkałaby się z odrzuceniem ze strony wykształconej części populacji, bo to, co w społeczności romskiej jest czynnikiem obciążającym (na przykład samodzielna nauka czytania i pisania), w społeczeństwie gadzio postrzegane jest jako czynnik łagodzący, oczywiście nie bez znacznej dozy paternalizmu. Hierarchiczna kaskada piętna działa tu odwrotnie (bo kobieta, bo autodydakta, bo cygańska poetka, bo chora psychicznie...), a także wykluczająco, bo czyni z Papuszy i jej poezji jedynie egzotyczne kuriozum. W każdym razie maleńka furtka do tej hipotetycznej ucieczki jest dla Papuszy nieosiągalna.

Tak więc w postaci Papuszy nawarstwiają się trzy wielkie anatemy: kobiecość, cygańskość (a to niesie ze sobą uprzedzenia etniczne, społeczne, ekonomiczne, rasowe) i inność (a ta zaczyna się od niezależności ducha, przechodzi przez pisanie wierszy, a kończy na chorobie psychicznej). W tym sensie Kuźniak zdaje się sugerować, że przypadek Papuszy jest tylko jednym z przykładów (paradygmatycznym w tym sensie, że skrajnym ${ }^{18}$ ) największego z grzechów: żeńskiej inności. "- Nie pisz wierszy, bo będziesz nieszczęśliwa"19 - beszta ją mąż.

\section{4}

Żeńska inność i jej wielorakie wyklęcia są więc, moim zdaniem, wielkimi tematami (opartymi oczywiście na portrecie Papuszy) książki Angeliki Kuźniak. W związku z tym w ogólnej debacie na temat gatunkowej przynależności takich dzieł, które sytuują się między biografią a reportażem, można by też pomyśleć o biografii-eseju (nie zaś o reportażu-eseju w sensie, jaki proponuje Ryszard Kapuściński w Imperium). Historycznie rzecz biorąc, definicje eseju były zawsze mało wyraziste. W tradycji anglosaskiej zwykło się go pojmować jako rodzaj rozprawy lub rozprawki. W swoim Dictionary of Literary Terms John A. Cuddon lakonicznie podaje:

esej (F essai 'próba') Utwór, zwykle prozą (...), który może składać się tylko z kilkuset słów (...) lub rozrosnąć się do rozmiarów książki (...), omawia on, formalnie lub nieformalnie, jeden lub wiele tematów. Jest to jedna z najbardziej elastycznych i otwartych na modyfikację form literackich ${ }^{20}$.

Trochę konkretniej, a zarazem, uwzględniając bardziej literackie odmiany eseju (tradycja Michela Montaigne’a), pisze w swoim słowniku Estébanez Calderón, który wymienia jego siedem typowych cech:

${ }^{18}$ Według Galant Ficowski myślał tak samo: „W ujęciu poety życiorys Papuszy jest tragiczny nieprzypadkowo" (A. Galant, dz. cyt., s. 180).

${ }^{19}$ A. Kuźniak, dz. cyt., s. 180.

${ }^{20}$ J.A. Cuddon, The Penguin Dictionary of Literary Terms and Literary Theory, poprawione przez C.E. Prestona, London 1999, s. 286 [tłum. - P.F.T.]. 
1. Zwięzłość (...) 2. Charakter perswazyjny i interpretacyjny (...) 3. Charakter konfesyjny (...) 4. Nastawienie na dialog (..) 5. Brak ustalonej struktury (..) 6. Różnorodność tematyczna (...) 7. Dążenie do wypracowania swoistego stylu ${ }^{21}$.

Jak się zdaje, Papuszę można by opisywać właśnie w tych dość pojemnych kategoriach. Być może to ryzykowne twierdzenie, że w przypadku Papuszy mamy do czynienia z esejem, bo akurat brak komentarzy, wywodów jawnie perswazyjnych jest jedną z podstawowych strategii literackich Kuźniak. Ale na tym polega niewątpliwie oryginalność tej książki i jedna z jej wielkich wartości, że rozpoznajemy w niej esej, mimo braku typowych wyznaczników eseistyczności: autorka stara się ukryć własne ja (choć tworzy pozór „empatycznego” narratora) oraz stroni od jawnej dyskursywności. I to właśnie ta nadwyżka eseistyczna może uczynić tę książkę atrakcyjną dla czytelników nieznających postaci Bronisławy Wajs lub nią niezainteresowanych. Zresztą Papusza jest, jak już wspomniałem, utworem formalnie niełatwym do zaklasyfikowania: można o nim tylko powiedzieć, że jest „portretem”22 pisanym przez „reporterkę"23.

\section{5}

W wywiadzie dla włoskiego blogu „PoloniCult” Angelika Kuźniak powiedziała: „Jako autorka odczuwam wielką satysfakcję, że przyczyniłam się do tego, że dałam jej [Papuszy - P.F.T.] nową młodość, nowe życie", a nawet stwierdziła, że „dzisiaj same wiersze Papuszy są tłumaczone na wiele języków”24. Rzeczywiście, niedawno ukazała się pierwsza antologia poezji Bronisławy Wajs w języku hiszpańskim. Jednak książka, którą Kuźniak jej poświęciła, jeszcze nie została wydana poza Polską: póki co szczególna biografia Papuszy i jej wiersze pozostają, można by rzec, wyłącznym dziedzictwem Polaków. Czy należy to przypisać temu, że historia Papuszy (z efektowną obecnością wielkich polskich poetów, takich jak Tuwim czy Ficowski) może zainteresować tylko polskiego czytelnika, który już wcześniej znał mit poetki cygańskiej? Naszym zdaniem to właśnie szeroki, eseistyczny zamysł książki czyni ją uniwersalną i potencjalnie atrakcyjną dla każdego współczesnego czytelnika.

W zeszłym roku sam przetłumaczyłem Papusze na hiszpański. Hiszpania to kraj, w którym mieszka ponad 600000 Romów z własną, bardzo silną i rozpoznawalną kulturą, ale jakże odległą od kultury polskich Cyganów! Niestety, jednak

${ }^{21}$ D. Estébanez Calderón, Diccionario de términos literarios, Madrid 2008, s. 327-328 [tłum. P.F.T.].

${ }^{22}$ Zob. przypis 7.

${ }^{23}$ Na pytanie Justyny Czechowskiej: „Skąd się wzięła Angelika Kuźniak - pisarka?” Angelika Kuźniak odpowiada: „Wolę nazywać się reporterką” (Z bohaterem muszę mieć chemię..., dz. cyt.).

${ }^{24}$ Angelika Kuźniak - io e Papusza..., dz. cyt. 
edycja książki została zablokowana przez wydawcę (nowe wykluczenie?). Jeśli wreszcie się ukaże, czy ma szansę przebić się na rynku wydawniczym, w dyskursie publicznym, w sercach i umysłach hiszpańskich czytelników? Jeśli znajdzie uznanie, nie mam wątpliwości, że stanie się tak dzięki eseistycznemu tonowi, który sączy się z tego osobistego portretu Papuszy. Właśnie dlatego, że biografią nie jest.

\section{Bibliografia}

Adamczewska I., Biografia reporterska w ujęciu komunikacyjnym na przyktadzie ksiażek Angeliki Kuźniak, „Annales Universitatis Paedagogicae Cracoviensis, Studia Poetica" 2016, IV.

Angelika Kúniak - io e Papusza, Intervista con Angelika Kuźniak, autrice della scuderia di Czarne specializzata in ritratti di donne speciali. Uno su tutti: Papusza (di Salvatore Greco), „PoloniCult, un blog italiano di cultura polacca”, 18.12.2017, https:// polonicult.com/Kuźniak-papusza/, dostęp: 19.05.2021.

Calderón Puerta A., Alotro lado del muro. Cuerpo y exclusión en "Junto a la vía del tren", de Zofia Natkowska [w:] Del instante a la eternidad: exégesis sobre "la espera" en la escritura de mujeres, red. J.L. Arráez Llobregat, A. Peral Crespo, Alacant 2012.

Cuddon J.A., The Penguin Dictionary of Literary Terms and Literary Theory, poprawione przez C.E. Prestona, London 1999.

Estébanez Calderón D., Diccionario de términos literarios, Madrid 2008.

Ficowski J., Demony cudzego strachu. Wspominki cygańskie, Warszawa 2013.

Galant A., „Życie a życie to jest duża różnica”. O biografiach Bronistawy Wajs - Papuszy, „Autobiografia. Literatura. Kultura. Media” 2014, nr 1 (2) 2014.

Horodecka M., Reportaż jako medium pamięci Innego na przyktadzie „Papuszy” Angeliki Kuźniak, „Tekstualia” 2017, nr 1 (48).

Kapuściński R., Imperium, Warszawa 1999.

Kuźniak A., Papusza, Wołowiec 2013.

Leibovici M., Autobiographies de transfuges. Karl Philipp Moritz, Richard Wright, Assia Djebar, Paris 2013.

Machowska M., Bronistawa Wajs - Papusza. Między biografią a legenda, Kraków 2011.

Nałkowska Z., Medaliony, Wrocław 2004.

Z bohaterem muszę mieć chemię. Z Angelika Kuźniak rozmawia Justyna Czechowska, „Kultura Liberalna", 26.01.2016, nr 368 (4), https://kulturaliberalna.pl/2016/01/26/z-bohaterem-musze-miec-chemie-angelika-Kuźniak/, dostęp: 17.05.2021.

Żyrek-Horodyska E., Reportaż biograficzny czy biografia reportażowa? Refleksje genologiczne i analiza przypadku, „Autobiografia. Literatura. Kultura. Media” 2018, nr 2 (11). 